\title{
A Case of Multiple Spontaneous Keloid Scars
}

\author{
Abdulhadi Jfri $^{\mathrm{a}}$ Nawal Rajeh $^{\mathrm{b}}$ Eman Karkashan $^{\mathrm{b}}$ \\ ${ }^{a}$ King Saud bin Abdulaziz University for Health Sciences and ${ }^{b}$ King Fahad General \\ Hospital, Jeddah, Saudi Arabia
}

\section{Key Words}

Keloid scars · Spontaneous keloids

\begin{abstract}
Keloid scars result from an abnormal healing response to cutaneous injury or inflammation that extends beyond the borders of the original wound. Spontaneous keloid scars forming in the absence of any previous trauma or surgical procedure are rare. Certain syndromes have been associated with this phenomenon, and few reports have discussed the evidence of single spontaneous keloid scar, which raises the question whether they are really spontaneous. Here, we present a 27 -year-old mentally retarded single female with orbital hypertelorism, broad nasal bridge, repaired cleft lip and high-arched palate who presented with progressive multiple spontaneous keloid scars in different parts of her body which were confirmed histologically by the presence of typical keloidal collagen. This report supports the fact that keloid scars can appear spontaneously and are possibly linked to a genetic factor. Furthermore, it describes a new presentation of spontaneous keloid scars in the form of multiple large lesions in different sites of the body.

(c) 2015 S. Karger AG, Basel
\end{abstract}

\section{Case Presentation}

A 27-year-old female presented to the dermatology clinic with skin lesions on her body which had been present for 10 years. These lesions had first appeared on the dorsum of the left foot and then spread to involve multiple sites. They were itchy, painful and gradually increasing in size over time and had never gone into involution or decreased in size. According to the patient and her mother there was no previous history of any form of trauma. The patient had no skin rash before development of the lesions. There were no similar skin lesions in the family. She was born at term as the result of a normal spontaneous vaginal deliv- 
ery after an uncomplicated pregnancy; she had a cleft lip, which was repaired. She left school in the 6 th grade because of a learning limitation. She has 10 siblings, 7 sisters and 3 brothers, who were all normal.

On examination, she had normal height and weight with normal vital signs. Her IQ is similar to a 7-year-old's. On the face she had orbital hypertelorism, a broad nasal bridge and a repaired cleft lip with a normally shaped head and no other anomalies. Orally she had a high-arched palate with severely decayed teeth and an appropriate voice tone. Skin examination revealed firm, irregularly shaped, hyperpigmented and slightly erythematous nodules with a shiny, smooth surface over the left dorsum of the foot, the right leg, the right thigh, the left elbow and the chest, involving the right breast (fig. 1). The other systems examined were unremarkable. Laboratory values were within normal ranges. An echocardiogram was done and was normal. A biopsy taken from two different lesions showed typical keloid with nodular thick hyalinized collagen fibers in the dermis, sparing the papillary dermis (fig. 2).

\section{Discussion}

A keloid scar is a benign hyperproliferative growth of dense fibrous tissue which results from an abnormal healing response to cutaneous injury that extends beyond the borders of the original wound, different from hypertrophic scars invading nearby normal skin. The term keloid dates from the 1800s and is derived from the Greek word 'chele', which means 'crab claw'. This is because of the scar's lateral extensions into normal tissue, which resemble the legs of a crab. A keloid scar is a clinical diagnosis, and one important consideration in reaching a keloid scar diagnosis is identifying a history of injury prior to the occurrence of the scar. Spontaneous keloid scars, forming in the absence of any previous trauma or surgical procedure, are rare.

Keloid scars commonly form firm, broad nodules that are usually erythematous with shiny surface nodules. These nodules are frequently pruritic and painful, and as a general rule they do not regress naturally. The most frequent sites of keloid scars are on the chest, the shoulders, the upper back extending to the neck and the earlobes. In general, individuals with dark skin color are at greater risk of developing keloids compared with whites [1]. The pathogenesis of keloid formation is inadequately understood, but keloids frequently result from trauma or inflammation of the skin. The most commonly reported causes of keloids comprise acne, folliculitis, chicken pox and injectable vaccinations as well as more obvious trauma (such as ear piercing or postsurgical intervention). In histology, keloids are characterized by increased collagen with thickened hyalinized collagen bundles referred to as keloidal collagen [2]. The etiology of keloids is possibly linked to both genetic and environmental factors; some individuals are more predisposed to keloid formation than others. Spontaneous keloid formation is rare, and there remains controversy over whether it is ever really spontaneous. Spontaneous keloid formation has been reported in certain syndromes, however. These are Dubowitz syndrome, Rubenstein-Taybi syndrome, Noonan syndrome, Goeminne syndrome and conjunctivo-corneal dystrophy [3-7]. Apart from these occurrences, single spontaneous keloid scar on the face has also been reported in two otherwise healthy men, in a 13-year-old on the preauricular region of the face and in an 81-year-old over the postauricular region $[8,9]$. Because of the rarity of spontaneous keloid scar, it is important to bear in mind the differential diagnosis of lesions resembling keloid scar, such as sarcoidosis and various malignant and benign tumors [10]. Our case had multiple lesions over different sites, which makes a history of unrecognized trauma seem unlikely. She had abnormal 
Jfri et al.: A Case of Multiple Spontaneous Keloid Scars

physical findings that did not fit with any of the previously mentioned syndromes associated with spontaneous keloids and that did not represent a particular syndrome.

There are many different therapies for keloids, varying widely in clinical efficacy. The most commonly used treatments and those for which there is perhaps the most evidence of efficacy are intralesional steroid injections, surgical excision, cryotherapy, laser removal and radiotherapy [11]. As these multiple large keloid scars caused the patient considerable discomfort, she was referred to a plastic surgeon for possible treatment with surgical excision and intralesional steroid injection.

\section{Acknowledgements}

Prof. Mohammed Satti and Dr. Bassam Alashi contributed the histopathology study.

\section{Statement of Ethics}

The authors state that the patient gave her informed consent to have her case report published.

\section{Disclosure Statement}

The authors have no conflicts of interest that are directly relevant to the content of this case report. No sources of funding were used to assist in the preparation of this paper.

\section{References}

1 Brissett AE, Sherris DA: Scar contractures, hypertrophic scars, and keloids. Facial Plast Surg 2001;17: 263-272.

2 Lee JY, Yang CC, Chao SC, Wong TW: Histopathological differential diagnosis of keloid and hypertrophic scar. Am J Dermatopathol 2004;26:379-384.

-3 Shilpashree P, Jaiswal AK, Kharge PM: Keloids: an unwanted spontaneity in Rubinstein-Taybi syndrome. Indian J Dermatol 2015;60:214.

4 Paradisi M, Angelo C, Conti G, Mostaccioli S, Cianchini G, Atzori F, Puddu P: Dubowitz syndrome with keloidal lesions. Clin Exp Dermatol 1994;19:425-427.

5 Gulec AT, Karaduman A, Seckin D: Noonan syndrome: a case with recurrent keloid formation. Cutis 2001;67:315-316.

-6 Goeminne L: A new probably X-linked inherited syndrome: congenital muscular torticollis, multiple keloids, cryptorchidism and renal dysplasia. Acta Genet Med Gemellol (Roma) 1968;17:439-467.

-7 Haugen $\mathrm{OH}$, Bertelsen T: A new hereditary conjunctivo-corneal dystrophy associated with dermal keloid formation. Acta Ophthalmol Scand 1998;76:461-465.

-8 Tiong WHC, Basiron NH: Challenging diagnosis of a rare case of spontaneous keloid scar. J Med Cases 2014;5:466-469.

-9 Monarca C, Maruccia M, Palumbo F, Parisi P, Scuderi N: A rare case of postauricular spontaneous keloid in an elderly patient. In Vivo 2012;26:173-175.

10 Ogawa R, Akaishi S, Hyakusoku H: Differential and exclusive diagnosis of diseases that resemble keloids and hypertrophic scars. Ann Plast Surg 2009;62:660-664.

$\checkmark 11$ Mustoe TA, Cooter RD, Gold MH, Hobbs FD, Ramelet AA, Shakespeare PG, Stella M, Téot L, Wood FM, Ziegler UE; International Advisory Panel on Scar Management: International clinical recommendations on scar management. Plast Reconstr Surg 2002;110:560-571. 
Case Reports in
Dermatology

Jfri et al.: A Case of Multiple Spontaneous Keloid Scars
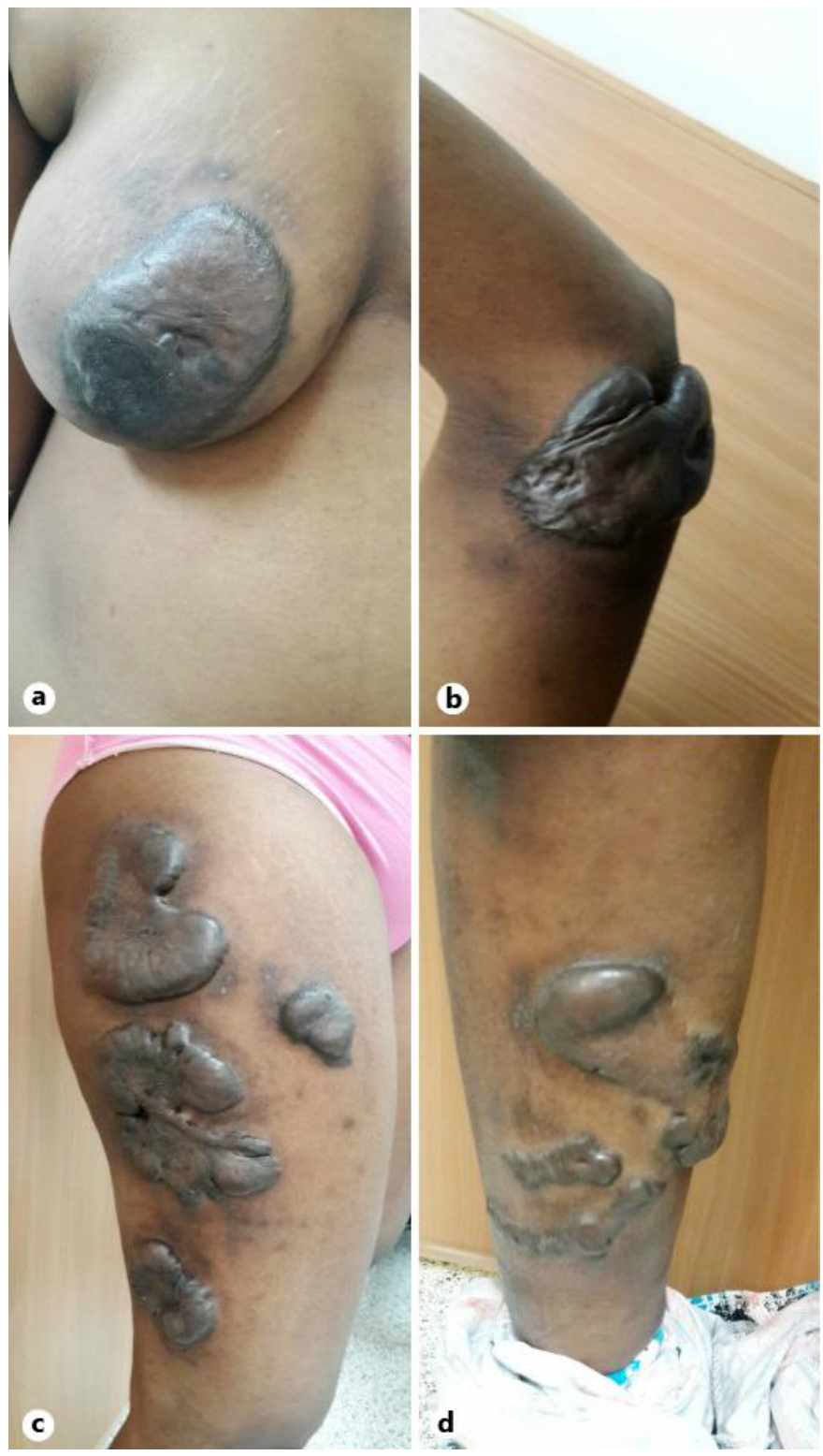

Fig. 1. Irregularly shaped hyperpigmented slightly erythematous nodules with a shiny, smooth surface over the right breast (a), left elbow (b), right thigh (c) and right lower limb (d). 
Jfri et al.: A Case of Multiple Spontaneous Keloid Scars
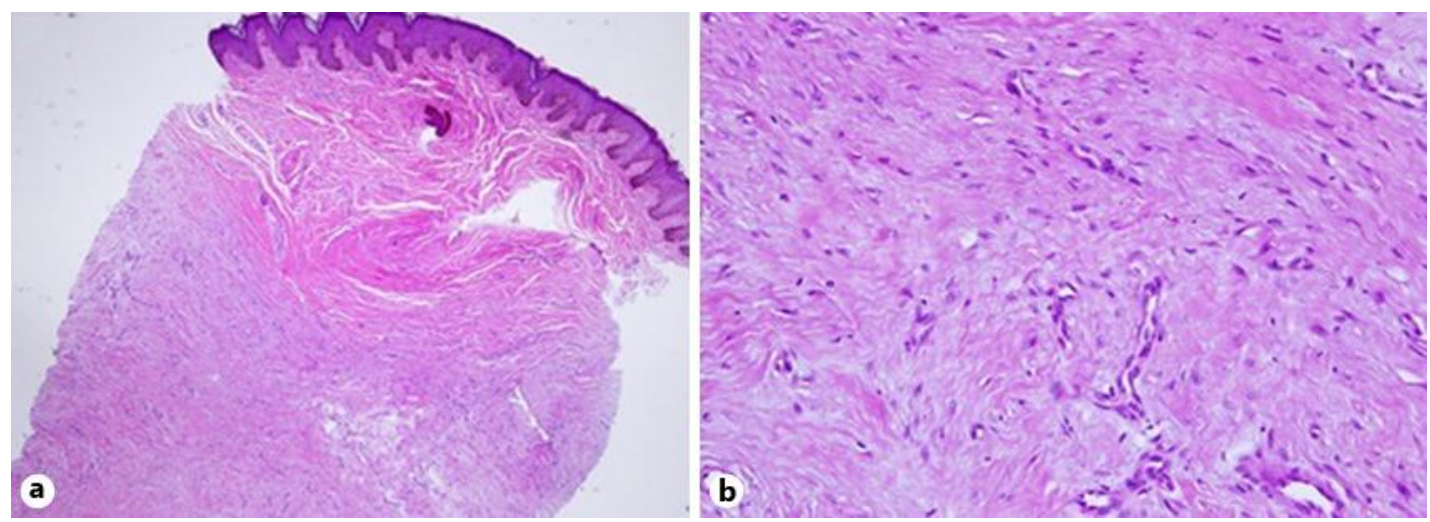

Fig. 2. Lesional biopsy at 250-fold (a) and 400-fold (b) magnification demonstrated typical keloid with nodular thick hyalinized collagen fibers in the dermis, sparing the papillary dermis. 